\title{
Screening and Basic Workup of a Patient with Peripheral Vascular Disease - A Primer of Physicians
}

\author{
Kolman SE*, Placido J, Patel A and Gowda RM \\ Icahn School of Medicine at Mount Sinai Beth Israel, Department of Cardiology, New York, United States
}

${ }^{*}$ Corresponding author: Kolman SE, Icahn School of Medicine at Mount Sinai Beth Israel, Department of Cardiology, New York, United States, Tel: 212-420-3363, E-mail: sakolman@mountsinai.org

Citation: Kolman SE, Placido J, Patel A, Gowda RM (2017) Screening and Basic Workup of a Patient with Peripheral Vascular Disease - A Primer of Physicians. J Clin Exp Res Cardiol 3(2): 202

Received Date: June 03, 2017 Accepted Date: July 19, 2017 Published Date: July 21, 2017

\begin{abstract}
Peripheral vascular disease (PVD) is a prevalent condition associated with significant morbidity and mortality in a variety of patient populations. When not properly recognized and treated, it can result in complications that include myocardial infarction, ischemic stroke, and cardiovascular death. In this review, we describe the risk factors, clinical presentation, diagnostic evaluation, treatment, and alternative diagnoses that can confound the diagnosis of PVD.
\end{abstract}

Keywords: Peripheral vascular disease; PVD; Peripheral Arterial Disease; PAD

\section{Introduction}

Peripheral artery disease (PAD) is as a narrowing or obstruction of at least one peripheral artery that compromises circulation. Obstruction occurs via deposition of lipid and fibrotic material between the intimal and medial layers of vessels. This results in plaque formation [1]. Plaques most commonly form in the distal superficial femoral and proximal popliteal arteries; areas commonly responsible for calf muscle claudication [2]. PAD may also be caused by thrombotic events, which occur rapidly and cause acute limb ischemia [3].

PAD affects more than 200 million people worldwide and is more prevalent in lower socioeconomic demographics. From 20002010, the prevalence in low and middle-income regions has increased 29\%, and in high-income regions 13\% [4]. In the United States, there are approximately 8.5 million people with PAD. PAD is more prevalent in high-income countries than low-income countries, specifically in older age groups, which is likely a function of increased survival times with co-morbid conditions [4]. PAD is also more prevalent in African American and Hispanic communities but equally prevalent in both men and women [5].

There is significant morbidity and mortality associated with PAD. PAD is strong independent risk factor of cardiovascular and cerebrovascular disease [6]. The 1-year incidence of cardiovascular death, myocardial infarction (MI), and ischemic stroke has been shown to be higher in PAD than in coronary heart disease [7]. The incidence of adverse limb outcomes, including worsening of symptoms, need for revascularization, and amputation was also found to be $26 \%$ over a 4 -year period [8]. In the elderly, PAD has costs Medicare approximately $\$ 4.37$ billion [9].

\section{Risk Factors}

The American College of Cardiology/American Heart Association (ACC/AHA) guidelines indicate the following groups are risk factors for PAD [10]:

- Patients older than 70 years

- Patients 50-69 years with a history of smoking or diabetes

- Patients 40-49 years with diabetes and at least one other risk factor for atherosclerosis, leg symptoms suggestive of claudication with exertion or ischemic pain at rest, abnormal lower extremity pulse examination, or known atherosclerosis disease

Smoking and diabetes are the strongest risk factors for PAD [4]. Markers of inflammation, and thrombosis, elevated lipoprotein(a) and homocysteine levels, and chronic kidney disease are also associated with peripheral arterial disease [11]. Men are more likely than women to have symptoms of claudication, though the prevalence of PAD among men and postmenopausal women is similar [12]. There is also a heritable component to PAD, and a positive family history may double the risk of susceptibility to PAD [13,14]. 


\section{Clinical Presentation and Diagnostic Evaluation}

Clinical presentation of PAD ranges from asymptomatic to threatened limb based on the degree of obstruction, number of arteries involved, and the activity level of the patients. The Rutherford Classification is the most commonly used system to classify acute and chronic limb ischemia. It incorporates clinical symptoms with objective findings, including Doppler, ABI (ankle-brachial index), and pulse volume recordings. ABI is the ratio of blood pressure at the ankle to upper arm and can help identify arterial occlusion from PAD, as described in a subsequent section. The chronic limb ischemia classification resembles Fontaine's classification with the addition of objective, noninvasive data. The acute limb ischemia classification divides an extremity into viable, threatened, or irreversibly damaged categories. The chronic and acute Rutherford Classifications are found in Tables 1 and 2, respectively [15-17].

\begin{tabular}{|c|c|c|c|}
\hline Grade & Category & Clinical Description & Objective Criteria \\
\hline 0 & 0 & $\begin{array}{l}\text { Asymptomatic - no hemodynami- } \\
\text { cally significant occlusive disease }\end{array}$ & Normal treadmill or reactive hyperemia test \\
\hline \multirow[t]{2}{*}{ I } & 1 & Mild claudication & $\begin{array}{l}\text { Completes treadmill exercise; } \mathrm{AP} \text { after exer- } \\
\text { cise }>50 \mathrm{mmHg} \text { but at least } 20 \mathrm{mmHg} \text { lower } \\
\text { than resting value }\end{array}$ \\
\hline & 2 & Moderate claudication & Between categories 1 and 3 \\
\hline \multirow{2}{*}{ II } & 3 & Severe claudication & $\begin{array}{c}\text { Cannot complete standard treadmill exercise, } \\
\text { and AP after exercise }<50 \mathrm{mmHg}\end{array}$ \\
\hline & 4 & Ischemic rest pain & $\begin{array}{l}\text { Resting AP }<40 \mathrm{mmHg} \text {, flat or barely pulsa- } \\
\text { tile ankle or metatarsal PVR; } \mathrm{TP}<30 \mathrm{mmHg}\end{array}$ \\
\hline \multirow{2}{*}{ III } & 5 & $\begin{array}{c}\text { Minor tissue loss - nonhealing ulcer, } \\
\text { focal gangrene with diffuse pedal } \\
\text { ischemia }\end{array}$ & $\begin{array}{l}\text { Resting AP }<60 \mathrm{mmHg} \text {, ankle or metatarsal } \\
\text { PVR flat or barely pulsatile; } \mathrm{TP}<40 \mathrm{mmHg}\end{array}$ \\
\hline & 6 & $\begin{array}{l}\text { Major tissue loss - extending above } \\
\text { TM level, functional foot no longer } \\
\text { salvageable }\end{array}$ & Same as category 5 \\
\hline
\end{tabular}

List of Abbreviations: AP: Ankle Pressure; PVR: Pulse Volume Recording; TM: Transmetatarsal; TP: Toe Pressure Table 1: Rutherford Classification for Chronic Limb Ischemia

\begin{tabular}{|c|c|c|c|c|}
\hline \multicolumn{2}{|c|}{} & \multicolumn{2}{|c|}{ Findings } & \multicolumn{2}{c|}{ Doppler Signal } \\
\hline Category & Description/Prognosis & Sensory Loss & Muscle Weakness & Arterial \\
\hline I. Viable & Not immediately threatened & None & None & Audible \\
\hline $\begin{array}{c}\text { IIa. Threatened } \\
\text { Marginally }\end{array}$ & Salvageable if promptly treated & $\begin{array}{c}\text { Minimal (toes) or } \\
\text { none }\end{array}$ & None & Inaudible \\
\hline $\begin{array}{c}\text { IIb. Threatened } \\
\text { Immediately }\end{array}$ & $\begin{array}{c}\text { Salvageable with immediate } \\
\text { revascularization }\end{array}$ & $\begin{array}{c}\text { More than toes, as- } \\
\text { sociated rest pain }\end{array}$ & Mild, moderate & Inaudible \\
\hline III. Irreversible & $\begin{array}{c}\text { Major tissue loss or permanent } \\
\text { nerve damage inevitable }\end{array}$ & $\begin{array}{c}\text { Profound, anes- } \\
\text { thetic }\end{array}$ & Profound, paralysis & Inaudible \\
\hline
\end{tabular}

Table 2: Rutherford Classification for Acute Limb Ischemia

Asymptomatic PAD is usually suspected during physical examination significant for decreased pedal pulses. Approximately 20$50 \%$ of patient $>50$ years old with PAD have asymptomatic presentation [18]. Intermittent claudication or classic claudication is defined as discomfort of a group of muscles, typically calf muscles, on exertion. It is alleviated by a few minutes of rest and usually represents $10-35 \%$ of patients with PAD.

Atypical leg pain is more common than classic claudication in those with low levels of activity and those with different perceptions of pain. Atypical claudication accounts for approximately 40-50\% of patients with PAD [19]. Acute/chronic limb ischemia represents a minimal percentage of the PAD population. Even though the incidence rate is low compared to the other classifications, it is the most severe and life threatening. Based on 2007 TASC II, if limb ischemia caused by an abrupt obstruction of perfusion by a thrombus presents within two weeks, it is considered acute. Similar presentations associated with rest limb pain and pulseless, with an onset lasting more than two weeks are considered chronic [20]. Skin temperature is an indicator of blood flow rate and can be useful as a marker of perfusion. Ischemic limbs are cool, and demarcation of temperature change can give rough indication of the level of occlusion.

Patients with PAD usually suffer from atherosclerotic disease in other vascular beds such as the coronary, carotid, and renal arteries. When PAD is suspected, the workup should include an ECG to assess for prior cardiac injury. CBC, standard chemistry, $\mathrm{PT} / \mathrm{PTT}$, and CPK should also be evaluated to assess for end-organ injury and factors that might contribute to a decrease in peripheral perfusion. There has been strong evidence suggesting a prothrombotic state in artherosclerotic disease. Therefore, anticardiolipin antibodies, homocysteine levels and PF4 antibodies should be evaluated. Elevated urinary leukotriene $\mathrm{E}_{4}$ has been 
observed in patients with restenosis and reocclusion after percutaneous transluminal angioplasty, and serial measurements may predict clinical manifestations in the months prior to symptom onset [21].

Questionnaires, including the Rose/WHO Questionnaire, Edinburgh Claudication Questionnaire, and San Diego Claudication Questionnaire, have been used extensively to assess the presence of claudication and detect the presence of PAD. Although often highly specific, they are relatively insensitive for the detection and diagnosis of PAD [22]. Other questionnaires, which include the Walking Impairment Questionnaire, the Short-Form-36 Physical Functioning Score, Peripheral Artery Questionnaire, and the PAD Quality of Life Questionnaire, are validated questionnaires that can help assess change in patient-reported walking performance and quality of life. The outcomes of these questionnaires are not interchangeable. Each outcome measures a different aspect of walking performance or quality of life, and should therefore be used in conjunction with other subjective and objective data to determine management [23].

A very detailed physical exam is necessary to diagnose or have a high suspicion for compromised peripheral circulation. Physical findings such as non-healing wound, skin discoloration and gangrene, rest pain, claudication, or decreased pedal pulses in addition to positive risk factors for atherosclerotic disease should trigger a workup for PAD. The resting ABI is the initial diagnostic test and is usually the only test needed in order to establish the diagnosis of PAD. The test measures the ratio of the systolic blood pressures at the lower (dorsalis pedis and posterior tibial) and upper (brachial) arteries in a supine position using a doppler sonography [24]. The classification is as follows: $<0.9$ is abnormal; a $0.91-0.99$ is borderline; $1.00-1.40$ is normal; $>1.40$ is not compressible. In the setting of a symptomatic patient with a normal or borderline resting ABI, additional testing is indicated, including exercise treadmill ABI to assess functional status.

There are two types of exercise treadmill testing: constant-loading testing and graded testing. Constant-load testing is performed at a single work rate and grade, whereas graded testing increases intensity a regular time intervals. The goal is to push patients to their maximally tolerated pain that results in an inability to walk any further. Constant-load protocols may be limited in that some patients with mild PAD may be able to walk for extended periods of time without claudication symptoms [25]. In contrast, graded treadmill testing has a large dynamic range that can reproducibly define a patient's peak PAD-limited peak walking and claudication onset time [26]. The 6-minute walking can also be used to evaluate functional status in PAD, though data supporting its use in PAD is less extensive than for graded exercise treadmill testing [25]. Nevertheless, the 6-minute walking test may more directly measure outcomes that are relevant to daily function and quality of life than treadmill testing [27].

Toe-brachial index (TBI) is the ratio between the toe pressure and the higher of the two brachial pressures. It is typically used in patients who are expected to have vessel stiffness, such as those with diabetes, chronic kidney disease or advanced age. It is also used in patients who have elevated ABIs $[28,29]$. The diagnostic criteria for normal vs. pathologic TBI remains ambiguous, but several guidelines and reviews recommend $<0.70$ be used as a cutoff $[10,20,30-34]$.

Other means of non-invasive hemodynamic assessment of PAD in the lower limbs include near infrared spectroscopy (NIRS) and measurement of transcutaneous partial pressure of oxygen $\left(\mathrm{TcPO}_{2}\right)$. NIRS can be used during a treadmill test or during a toe flexion test in patients unable to walk to objectively define PAD presence or severity and foot perfusion [35]. TcPO 2 can provide evidence of exercise-induced regional blood flow impairment during both exercise and recovery [36,37]. Normal TcPO levels are approximately $60 \mathrm{mmHg}$. Levels of $20 \mathrm{mmHg}$ or less are indicative of severely reduced blood flow and indicate revascularization is required. More liberal use of $\mathrm{TcPO}_{2}$ should be considered in diabetics as they may be asymptomatic, often due to neuropathy and lack of activity, but have significant PAD [38].

Computed tomographic angiography (CTA) and magnetic resonance angiography (MRA) are useful to diagnose anatomic location and degree of stenosis in patients with symptomatic PAD in whom revascularization is being considered. If CT or MRA are not possible or the results are insufficient for making a decision on revascularization, invasive angiography may be considered [39]. CT angiography is widely available, requires a short scanning time, and provides high-resolution images that can be threedimensionally reconstructed. It does, however, require vascular contrast and may not provide delineation of heavily calcified or small distal vessels. MRA does not use radiation and also provides good spatial resolution but is technically more challenging that CT angiography, cannot be used in patients with certain metallic or electronic implants, and carries a risk of nephrogenic systemic fibrosis when gadolinium is used in patients with CKD [12].

According to the ACC/AHA 2005 Practice Guidelines, subjects with claudication should be screened using Doppler ultrasonography (US). Doppler US can be used for the determination of anatomic localization, grade of stenosis, and for follow-up of post-operative femoropopliteal and femorotibial-pedial vein grafts. Doppler US is also recommended for selection of subjects that could benefit from endovascular intervention and for follow-up after endovascular treatment. With respect to revascularization surgery, doppler US can identify the level of arterial segments that require surgical anastomoses, however its utility, in the identifying long-term success of percutaneous transluminal angioplasty is not clear [40,41].

\section{Treatment}

Management of patients with PAD should include an exercise program, medical therapy to reduce cardiovascular risk, and when indicated, revascularization [42]. In patients with PAD and no other cardiovascular disease, the use of multiple preventative therapies was associated with a 65\% lower all-cause mortality (HR: 0.35, p=0.02) [43]. The American College of Cardiology 
Foundation (ACCF) and American Heart Association (AHA) guidelines also suggest a multi-disciplined approach to treating lower extremity PAD, which includes smoking cessation, lipid lowering therapy, diabetes and hypertension control, and exercise therapy [10].

\section{Exercise}

The goal of an exercise regimen in those physically limited secondary to PAD is to improve functional status and quality of life. Physical activity in patients with PAD is associated with decreased all-cause and cardiovascular mortality [44,45]. 12-week supervised exercise programs have been shown to improve exercise performance and quality of life in PAD [46]. They are also more cost-effective than endovascular revasculization, as is a stepped approach of exercise therapy followed by endovascular revascularization than revascularization alone $[48,47]$. Supervised exercise in a hospital or outpatient facility is recommended for all patients with PAD [49]. Structured or home-based exercise may be considered as an alternative treatment modality as it has not been shown as efficacious as supervised exercise [50]. Generally, an exercise regimen should include treadmill exercise training for 45 minutes, 3-5 days per week. Patients should increase workload as able, stopping when symptoms reach a mild-moderate discomfort level and resuming when symptoms are relieved [51,52]. Nordic walking (NW) exercises may also be recommended, as they have been shown to increase walking distance in patients with PAD [53,54]. They involve a 10-minute warm-up, a 45-minute session of walking at a pace dictated by a calculated training heart rate, and a 5-minute low-intensity cool down 5 times per week for 2 months [55].

\section{Smoking Cessation}

Smoking cessation is one of the most important lifestyle modifications to prevent chronic limb ischemia, amputation, and major adverse cardiac events in patients with PAD [42]. Tobacco cessation has been shown to lower 5-year mortality and improve amputation-free survival [56]. Cessation should be encouraged at every office visit.

\section{Diet Modification}

Improper nutrient intake has been shown to contribute to the development and progression of PAD [57-62]. The 2013 AHA/ACC Guidelines broadly emphasize diets rich in fruits, vegetables, whole grains, legumes, as well as limiting calories from saturated fats to no more than 5-6\% of total calorie intake, reducing dietary monounsaturated fats, and minimizing intake of foods rich in trans-fats, which are commonly found in milk, animal fats, and some vegetable oils. The Dietary Approaches to Stop Hypertension (DASH) diet is the only diet to hold a class IA recommendation for primary and secondary prevention of cardiovascular disease and should be recommended to all patients with PAD [63]. The Mediterranean diet is another reasonable alternative.

\section{Diabetes Treatment}

Treatment of diabetes does not reduce the risk of cardiovascular events, but it may lower the risks of neuropathy and microvascular disease [64]. This recommendation applies to patients with PAD and diabetes at risk for debilitating foot ulceration. Glycemic goals should be based on age, duration of diabetes, and relevant comorbidities rather than tight glycemic control, which may increase mortality among patients with cardiovascular disease [65]. Proper foot care and daily foot inspections are also recommended.

\section{Cilostazol}

Cilostazol should be considered in patients with intermittent claudication refractory to exercise therapy and smoking cessation. It may be used in combination with either aspirin or clopidogrel but is contraindicated in patients with heart failure. Cilostazol has been shown to increase maximal and pain-free walking distances in patients with moderate-severe claudication [66]. This benefit, however, may take up to 4 months to become apparent [67]. Although it appears to be safe long-term, adherence is low due to side effects which include headache, palpations, and diarrhea [67].

\section{ACE Inhibitors}

ACE inhibitors (ACEIs) should be considered in both symptomatic and asymptomatic patients with lower extremity PAD to reduce the risk of adverse cardiovascular events [10]. Data for their use derives from the HOPE trial, which evaluated the role of ramipril in patients who were at high risk for cardiovascular events that did not have left ventricular dysfunction or heart failure [68]. The study found significant reductions in rates of death, myocardial function, and stroke. ACEIs also reduce blood pressure, and while one trial suggested systolic blood pressure goals of less than $120 \mathrm{mmHg}$, blood pressure targets remain a controversial issue $[12,69]$.

\section{Statins}

High-intensity statins are indicated in PAD to reduce the risk of cardiovascular disease. Treatment should be based on cardiovascular risk rather than low-density lipoprotein targets [70]. Data for their use derives mostly from the Heart Protection Study (HPS), which showed reduction in first major vascular (MI, coronary death, stroke, or resvasculariztion) and PAD events [71]. Statins have also been shown to reduce in adverse limb outcomes including amputation and are associated with combined endpoint reductions in worsening claudication, new CLI, and/or new revascularization [72,73]. 


\section{Antiplatelet Agents}

The 2005 and 2011 ACCF/AHA Guidelines recommend aspirin for patients with symptomatic PAD (IA recommendation), and asymptomatic patients with PAD and either an $\mathrm{ABI}<0.9$ (IIA recommendation) or ABI of 0.9-0.99 (IIB recommendation) [10]. Recent data from the Prevention of Progression of Arterial Disease and Diabetes (POPADAD) and Aspirin for Asymptomatic Atherosclerosis (AAA) trials, however, showed no reduction in fatal and nonfatal cardiovascular events or revascularization with aspirin monotherapy [74,75]. These guidelines may change with future revisions, so their use should be at the discretion of the clinician, taking other co-morbidities into account [42]. Vorapaxar is another antiplatelet medication that can be considered in patients with PAD without a history of stroke. Vorapaxar was shown to reduce the risk of cardiovascular death or ischemic events in patients with atherosclerotic vascular disease [76]. In a subgroup of patients with PAD, it also reduced the risk of acute limb ischemia and peripheral-revascularization events [77]. Vorapaxar is contraindicated in patients with a history stroke because of its increased risk of bleeding, specifically intracranial hemorrhage.

\section{Clopidogrel}

Clopidogrel can be considered for both monotherapy and dual-antiplatelet therapy (DAPT) in patients with PAD. The Clopidogrel Versus Aspirin in Patients at Risk of Ischemic Events (CAPRIE) trial showed benefit in long-term administration of clopidogrel to patients with atherosclerotic vascular disease reduces risk of ischemic stroke, MI, or vascular death when compared with aspirin [78]. Data for DAPT has been mixed and is most commonly used after endovascular intervention. A propensity-matched observational study among patients undergoing endovascular intervention showed a significant reduction in MACE among patients taking DAPT versus aspirin monotherapy [79]. Other trials, such as the Clopidogrel for High Atherothrombotic Risk and Ischemic Stabilization, Management and Avoidance (CHARISMA) and Clopidogrel and Acetylsalicylic Acid in Bypass Surgery for Peripheral Artery Disease (CASPAR) trials showed no overall significant benefit from daily aspirin and clopidogrel) when compared to daily clopidogrel use [80,81].

\section{Revascularization Therapy}

Revascularization therapy should be considered in symptomatic patients with a reasonable likelihood of symptom reduction despite optimal pharmacological therapy and exercise program participation. Revascularizaiton is also indicated for limb salvage in critical limb ischemia (CLI) [12]. Generally, if a patient is a candidate for both endovascular and open surgery, the less-invasive endovascular option is preferred [42]. The goal of revascularization in claudication is relief of symptoms. The goal in CLI is rapid reperfusion of ischemic tissue to prevent amputation and restore ambulation [42].

Endovascular-first approaches are recommended for aortoiliac lesions, femoral-popliteal lesions, infrapopliteal lesions, and CLI $[10,82]$. In aortoiliac and femoral-popliteal disease, endovascular intervention is preferred due to high procedural success rates and low risk [82]. In common femoral disease, endarterectomy has traditionally been used, but there is data to suggest endovascular interventions have high success rates [42,83]. Endovascular therapy in infrapopliteal disease has a low rate of periprocedural events, with mortality rates in observational series $<1 \%$ [42]. Surgical bypass should be considered when endovascular therapy is unsuccessful or is not feasible from an anatomical standpoint, including attempts at retrograde percutaneous angioplasty if intergrade access recanalization is not possible [12].

\section{Other Differential Diagnoses}

PAD should not be confused with other diagnoses that it symptomatically mimics. Described below are contrasts between PAD and other common disease processes.

\section{Spinal Canal Stenosis}

Spinal canal stenosis may resemble PAD when there is lumbar involvement due to weakness, pain, and numbness of the legs. The symptoms of lumbar stenosis may be worse with ambulation, present bilaterally, and can present as intermittent, crampy pain that can resemble PAD. Unlike PAD however, lumbar stenosis is exacerbated by standing erect and alleviated by laying supine. The symptoms of PAD will remain unchanged during flexion and extension of the spine. Lumbar stenosis is not exacerbated with biking or uphill ambulation like PAD. Additionally, pain in lumbar stenosis radiates from the back to the leg, whereas pain in PAD radiates from the leg to the back.

\section{Peripheral Neuropathy}

Peripheral neuropathy is damage or disease affecting nerves that can impair sensation, movement, gland, and organ function. Diabetic neuropathy, one of the most common peripheral neuropathies, typically presents with a stocking-glove distribution that results may result in numbness, burning, tingling, impaired fine coordination, and difficulties with balance. The reliability of reporting these symptoms, however, is inconsistent, so clinicians should maintain a high degree of suspicion if the patient is diabetic. Diabetes is a strong risk factor for PAD and many diabetics often have coexisting PAD. The presenting history of gradually worsening peripheral sensation not relieved by rest may indicate diabetic neuropathy. Furthermore, diabetic neuropathy presents bilaterally, and PAD may present unilaterally depending on where the occlusion is. ABIs should be performed in any diabetic suspected of having PAD for further confirmation. 


\section{Peripheral Nerve Pain from a Herniated Disk Affecting the Sciatic Nerve}

When a herniated disk affects the sciatic nerve, it may present with muscular weakness and pulsating radicular pain that comes and goes. Unlike PAD, the pain will often follow the distribution of the sciatic nerve and is affected by position. The history may also suggest an inciting event, such as a back injury, that would suggest herniation rather than PAD. Straight-leg may also be useful in differentiating the etiology.

\section{Osteoarthritis of the Knee}

The patellofemoral joint and medial tibiofemoral joint are most commonly associated with osteoarthritis of the knee. Pain is usually isolated to the anterior knee, but in severe disease may radiate distally. Posterior knee pain is rare unless there is a concurrent Baker's cyst. Pain is usually made worse by climbing up or going down stairs or inclines and rising from a seated position, whereas in PAD these symptoms are less dramatic. Physical exam may reveal bony deformities, including fixed flexion and/or varus presentation. X-rays may show osteophyte formation, joint space narrowing, subchondral sclerosis, and subchondral cyst formation, findings not commonly associated with PAD.

\section{Venous Claudication}

Chronic lower extremity venous disease refers to the presence of morphological or functional venous abnormalities that can cause lower extremity pain and discomfort. Visibly dilated veins, skin changes and ulcerations, tired and heavy legs, and limb swelling are frequently associated venous disease. If claudication symptoms occur, they typically present with variable degrees of leg swelling, varicosities, and increased discomfort with limb dependency, features that are not typically seen in PAD.

\section{Symptomatic Baker's Cyst}

A Baker's cyst is a swelling in the popliteal fossa due to enlargement of the gastrocnemius-semimembraneous bursa. Symptoms include posterior knee pain, knee stiffness, and the presence of a swelling or mass behind the knee detected on extension at the knee. Symptoms may worsen with activity but usually correlate with the size of the cyst, associated joint pathology, and the presence of complications that include dissection and rupture. Ultrasound and plain radiography can be used to confirm the diagnosis if it remains in question.

\section{Chronic Compartment Syndrome}

Chronic compartment syndrome results from increased pressure of the osteofacial planes of the muscle compartment due to overuse, typically from running. Unlike PAD, chronic compartment syndrome affects young endurance athletes, particularly those who run extensively. The pain is often bilateral in nature and localized to the lower leg, begins within minutes of running, and resolves within 10-20 minutes of activity cessation.

\section{Restless Leg Syndrome}

Restless leg syndrome is a sleep-related movement disorder characterized by uncomfortable need to move one's legs during periods of inactivity, sometimes accompanied by tingling, cramping, and itchiness. Symptoms usually occur in the evenings and unlike PAD, are transiently relieved by movement.

\section{References}

1. Creager MA, Belkin M, Bluth EI, Casey DE Jr, Chaturvedi S, et al. (2012) 2012 ACCF/AHA/ACR/SCAI/SIR/STS/SVM/SVN/SVS Key data elements and definitions for peripheral atherosclerotic vascular disease: a report of the American College of Cardiology Foundation/American Heart Association Task Force on Clinical Data Standards (Writing Committee to develop Clinical Data Standards for peripheral atherosclerotic vascular disease). J Am Coll Cardiol 59: $294-357$.

2. Kasapis C, Gurm HS (2009) Current Approach to the Diagnosis and Treatment of Femoral-Popliteal Arterial Disease. A Systematic Review. Curr Cardiol Rev 5: 296-311.

3. O'Connell JB, Quiñones-Baldrich WJ (2009) Proper evaluation and management of acute embolic versus thrombotic limb ischemia. Semin Vasc Surg 22: 10-6.

4. Fowkes FG, Rudan D, Rudan I, Aboyans V, Denenberg JO, et al. (2013) Comparison of global estimates of prevalence and risk factors for peripheral artery disease in 2000 and 2010: a systematic review and analysis. Lancet 382: 1329-40.

5. CDC (2016) Peripheral Arterial Disease (PAD) Fact Sheet, USA.

6. Golomb BA, Dang TT, Criqui MH (2006) Peripheral arterial disease: morbidity and mortality implications. Circulation 114: 688-99.

7. Bhatt DL, Steg PG, Ohman EM, Hirsch AT, Ikeda Y (2006) International prevalence, recognition, and treatment of cardiovascular risk factors in outpatients with atherothrombosis. JAMA 295: 180-9.

8. Steg PG, Bhatt DL, Wilson PW, D’Agostino R Sr, Ohman EM (2007) One-year cardiovascular event rates in outpatients with atherothrombosis. JAMA 297: 1197206.

9. Hirsch AT, Hartman L, Town RJ, Virnig BA (2008) National health care costs of peripheral arterial disease in the Medicare population. Vasc Med 13: 209-15.

10. Rooke TW, Hirsch AT, Misra S, Sidawy AN, Beckman JA, et al. (2013) Management of patients with peripheral artery disease (compilation of 2005 and 2011 ACCF/AHA Guideline Recommendations): a report of the American College of Cardiology Foundation/American Heart Association Task Force on Practice Guidelines. J Am Coll Cardiol 61: 1555-70.

11. Khawaja FJ, Kullo IJ (2009) Novel markers of peripheral arterial disease. Vasc Med 14: 381-92.

12. Kullo IJ, Rooke TW (2016) Clinical Practice. Peripheral Artery Disease. N Engl J Med 374: 861-71. 
13. Khaleghi M, Isseh IN, Bailey KR, Kullo IJ (2014) Family history as a risk factor for peripheral arterial disease. Am J Cardiol 114: 928-32.

14. Wahlgren CM, Magnusson PK (2011) Genetic influences on peripheral arterial disease in a twin population. Arterioscler Thromb Vasc Biol 31 : 678-82.

15. International Society for Cardiovascular Surgery (1986) Suggested standards for reports dealing with lower extremity ischemia. Prepared by the Ad Hoc Committee on Reporting Standards, Society for Vascular Surgery/North American Chapter, International Society for Cardiovascular Surgery. J Vasc Surg 4: 80-94.

16. Hardman RL, Jazaeri O, Yi J, Smith M, Gupta R (2014) Overview of Classification Systems in Peripheral Artery Disease. Semin Intervent Radiol 31 : 378-88.

17. Rutherford RB, Baker JD, Ernst C, Johnston KW, Porter JM, et al. (1997)Recommended standards for reports dealing with lower extremity ischemia: revised version. J Vasc Surg 26: 517-38.

18. McDermott MM, Guralnik JM, Ferrucci L, Tian L, Liu K, et al. (2008) Asymptomatic peripheral arterial disease is associated with more adverse lower extremity characteristics than intermittent claudication. Circulation 117: 2484-91.

19. McDermott MM, Greenland P, Liu K, Guralnik JM, Criqui MH, et al. (2001) Leg symptoms in peripheral arterial disease: associated clinical characteristics and functional impairment. JAMA 286: 1599-606.

20. Norgren L, Hiatt WR, Dormandy JA, Nehler MR, Harris KA, et al. (2006) Inter-Society Consensus for the Management of Peripheral Arterial Disease (TASC II). Eur J Vasc Endovasc Surg 33: S1-75.

21. Maga P, Sanak M, Rewerska B, Maga M, Jawien J, et al. (2016) Urinary cysteinyl leukotrienes in one-year follow-up of percutaneous transluminal angioplasty for peripheral arterial occlusive disease. Atherosclerosis 249: 174-80.

22. Schorr EN, Treat-Jacobson D (2013) Methods of symptom evaluation and their impact on peripheral artery disease (PAD) symptom prevalence: a review. Vasc Med 18: 95-111.

23. McDermott MM (2016) Lower extremity manifestations of peripheral artery disease: the pathophysiologic and functional implications of leg ischemia. Circ Res 116: 1540-50.

24. Gerhard-Herman MD, Gornik HL, Barrett C, Barshes NR, Corriere MA, et al. (2017) 2016 AHA/ACC Guideline on the Management of Patients With Lower Extremity Peripheral Artery Disease: Executive Summary: A Report of the American College of Cardiology/American Heart Association Task Force on Clinical Practice Guidelines. J Am Coll Cardiol 69: 1465-508.

25. Hiatt WR, Rogers RK, Brass EP (2014) The treadmill is a better functional test than the 6-minute walk test in therapeutic trials of patients with peripheral artery disease. Circulation 130: 69-78.

26. Hiatt WR, Goldstone J, Smith SC Jr, McDermott M, Moneta G, et al. (2008) Atherosclerotic Peripheral Vascular Disease Symposium II: nomenclature for vascular diseases. Circulation 118: 2826-9.

27. McDermott MM, Guralnik JM, Criqui MH, Liu K, Kibbe MR, et al. (2014) Six-minute walk is a better outcome measure than treadmill walking tests in therapeutic trials of patients with peripheral artery disease. Circulation 130: 61-8.

28. Potier L, Halbron M, Bouilloud F, Dadon M, Le Doeuff J, et al. (2009) Ankle-to-brachial ratio index underestimates the prevalence of peripheral occlusive disease in diabetic patients at high risk for arterial disease. Diabetes Care 32: e44.

29. Suominen V, Uurto I, Saarinen J, Venermo M, Salenius J (2010) PAD as a risk factor for mortality among patients with elevated ABI--a clinical study. Eur J Vasc Endovasc Surg 39: 316-22.

30. Ankle Brachial Index Collaboration, Fowkes FG, Murray GD, Butcher I, Heald CL, et al. (2008) Ankle brachial index combined with Framingham Risk Score to predict cardiovascular events and mortality: a meta-analysis. JAMA 300: 197-208.

31. Azam SM, Carman TL (2011) Diagnostic approach to peripheral arterial disease. Cardiol Clin 29: 319-29.

32. Begelman SM, Jaff MR (2006) Noninvasive diagnostic strategies for peripheral arterial disease. Cleve Clin J Med 73: S22-29.

33. Chan D, Anderson ME, Dolmatch BL (2010) Imaging evaluation of lower extremity infrainguinal disease: role of the noninvasive vascular laboratory, computed tomography angiography, and magnetic resonance angiography. Tech Vasc Interv Radiol 13: 11-22.

34. Lau JF, Weinberg MD, Olin JW (2011) Peripheral artery disease. Part 1: clinical evaluation and noninvasive diagnosis. Nat Rev Cardiol 8: 405-18.

35. Manfredini F, Lamberti N, Rossi T, Mascoli F, Basaglia N, et al. (2017) A Toe Flexion NIRS assisted Test for Rapid Assessment of Foot Perfusion in Peripheral Arterial Disease: Feasibility, Validity, and Diagnostic Accuracy. Eur J Vasc Endovasc Surg S1078-5884(17)30271-X.

36. Abraham P, Picquet J, Bouyé P, L'Hoste P, Enon B, et al. (2005) Transcutaneous oxygen pressure measurements (tcpO2) at ankle during exercise in arterial claudication. Int Angiol 24: 80-8.

37. Signolet I, Henni S, Colas-Ribas C, Feuilloy M, Picquet J, Abraham P (2016) Prevalence and Causes of Normal Exercise Oximetry in the Calf in Patients with Peripheral Artery Disease and Limiting Calf Claudication. Eur J Vasc Endovasc Surg 51: 572-8.

38. Andersen CA (2010) Noninvasive assessment of lower-extremity hemodynamics in individuals with diabetes mellitus. J Am Podiatr Med Assoc 100: 406-11.

39. Gerhard-Herman, Gornik HL, Barrett C, Barshes NR, Corriere MA, et al. (2017) 2016 AHA/ACC Guideline on the Management of Patients With Lower Extremity Peripheral Artery Disease: A Report of the American College of Cardiology/American Heart Association Task Force on Clinical Practice Guidelines. J Am Coll Cardiol 69: 1465-508.

40. Hirsch AT, Haskal ZJ, Hertzer NR, Bakal CW, Creager MA, et al. (2006) ACC/AHA 2005 guidelines for the management of patients with peripheral arterial disease (lower extremity, renal, mesenteric, and abdominal aortic): executive summary a collaborative report from the American Association for Vascular Surgery/ Society for Vascular Surgery, Society for Cardiovascular Angiography and Interventions, Society for Vascular Medicine and Biology, Society of Interventional Radiology, and the ACC/AHA Task Force on Practice Guidelines (Writing Committee to Develop Guidelines for the Management of Patients With Peripheral Arterial Disease) endorsed by the American Association of Cardiovascular and Pulmonary Rehabilitation; National Heart, Lung, and Blood Institute; Society for Vascular Nursing; TransAtlantic Inter-Society Consensus; and Vascular Disease Foundation. J Am Coll Cardiol 47: $1239-312$.

41. Verim S, Tasci I (2013) Doppler ultrasonography in lower extremity peripheral arterial disease. Turk Kardiyol Dern Ars 41: $248-55$.

42. Olin JW, White CJ, Armstrong EJ, Kadian-Dodov D, Hiatt WR (2016) Peripheral Artery Disease: Evolving Role of Exercise, Medical Therapy, and Endovascular Options. J Am Coll Cardiol 67: 1338-57.

43. Pande RL, Perlstein TS, Beckman JA, Creager MA (2011) Secondary prevention and mortality in peripheral artery disease: National Health and Nutrition Examination Study, 1999 to 2004. Circulation 124: 17-23.

44. Chang P, Nead KT, Olin JW, Myers J, Cooke JP, Leeper NJ (2015) Effect of physical activity assessment on prognostication for peripheral artery disease and mortality. Mayo Clin Proc 90: 339-45.

45. Sakamoto S, Yokoyama N, Tamori Y, Akutsu K, Hashimoto H, et al. (2009) Patients with peripheral artery disease who complete 12-week supervised exercise training program show reduced cardiovascular mortality and morbidity. Circ J 73: 167-73. 
46. Mays RJ, Rogers RK, Hiatt WR, Regensteiner JG (2013) Community walking programs for treatment of peripheral artery disease. J Vasc Surg 58: 1678-87. 47. Spronk S, Bosch JL, den Hoed PT, Veen HF, Pattynama PM, et al. (2008) Cost-effectiveness of endovascular revascularization compared to supervised hospitalbased exercise training in patients with intermittent claudication: a randomized controlled trial. J Vasc Surg 48: 1472-80.

48. Fokkenrood HJ, Scheltinga MR, Koelemay MJ, Breek JC, Hasaart F, et al. (2014) Significant savings with a stepped care model for treatment of patients with intermittent claudication. Eur J Vasc Endovasc Surg 48: 423-9.

49. Murphy TP, Cutlip DE, Regensteiner JG, Mohler ER, Cohen DJ, et al. (2015) Supervised exercise, stent revascularization, or medical therapy for claudication due to aortoiliac peripheral artery disease: the CLEVER study. J Am Coll Cardiol 65: 999-1009.

50. Parmenter BJ, Dieberg G, Smart NA (2015) Exercise training for management of peripheral arterial disease: a systematic review and meta-analysis. Sports Med 45: 231-44.

51. Bronas UG, Hirsch AT, Murphy T, Badenhop D, Collins TC, et al. (2009) Design of the multicenter standardized supervised exercise training intervention for the claudication: exercise vs endoluminal revascularization (CLEVER) study. Vasc Med 14: 313-21.

52. Hamburg NM, Balady GJ (2011) Exercise rehabilitation in peripheral artery disease: functional impact and mechanisms of benefits. Circulation $123:$ 87-97.

53. Bulińska K, Kropielnicka K, Jasiński T, Wojcieszczyk-Latos J, Pilch U, et al. (2016) Nordic pole walking improves walking capacity in patients with intermittent claudication: a randomized controlled trial. Disabil Rehabil 38: 1318-24.

54. Oakley C, Zwierska I, Tew G, Beard JD, Saxton JM (2008) Nordic poles immediately improve walking distance in patients with intermittent claudication. Eur J Vasc Endovasc Surg 36: 689-694.

55. Girold S, Rousseau J, Le Gal M, Coudeyre E, Le Henaff J (2017) Nordic walking versus walking without poles for rehabilitation with cardiovascular disease: Randomized controlled trial. Ann Phys Rehabil Med S1877-0657.

56. Armstrong EJ, Wu J, Singh GD, Dawson DL, Pevec WC, et al. (2014) Smoking cessation is associated with decreased mortality and improved amputation-free survival among patients with symptomatic peripheral artery disease. J Vasc Surg 60: 1565-71.

57. Nosova EV, Conte MS, Grenon SM (2015) Advancing beyond the "heart-healthy diet" for peripheral arterial disease. J Vasc Surg 61: 265-74.

58. Tornwall ME, Virtamo J, Haukka JK, Aro A, Albanes D, et al. (2000) Prospective study of diet, lifestyle, and intermittent claudication in male smokers. Am J Epidemiol 151: 892-901.

59. Lane JS, Magno CP, Lane KT, Chan T, Hoyt DB (2008) Nutrition impacts the prevalence of peripheral arterial disease in the United States. J Vasc Surg 48: 897904.

60. Klipstein-Grobusch K, den Breeijen JH, Grobbee DE, Boeing H, Hofman A, et al. (2001) Dietary antioxidants and peripheral arterial disease : the Rotterdam Study. Am J Epidemiol 154: 145-9.

61. Ciccarone E, Di Castelnuovo A, Salcuni M, Siani A, Giacco A, et al. (2003) A high-score Mediterranean dietary pattern is associated with a reduced risk of peripheral arterial disease in Italian patients with Type 2 diabetes. J Thromb Haemost 1: 1744-52.

62. Brostow DP, Hirsch AT, Collins TC, Kurzer MS (2012) The role of nutrition and body composition in peripheral arterial disease. Nat Rev Cardiol 9: 634-43.

63. Eckel RH, Jakicic JM, Ard JD, de Jesus JM, Houston Miller N, et al. (2013) AHA/ACC guideline on lifestyle management to reduce cardiovascular risk: a report of the American College of Cardiology/American Heart Association Task Force on Practice Guidelines. J Am Coll Cardiol 63: 2960-84.

64. UK Prospective Diabetes Study (UKPDS) (1998) Group Intensive blood-glucose control with sulphonylureas or insulin compared with conventional treatment and risk of complications in patients with type 2 diabetes (UKPDS 33). Lancet 352: 837-53.

65. ACCORD Study Group, Gerstein HC, Miller ME, Genuth S, Ismail-Beigi F et al. (2011) Long-term effects of intensive glucose lowering on cardiovascular outcomes. N Engl J Med 364: 818-28.

66. Thompson PD, Zimet R, Forbes WP, Zhang P (2002) Meta-analysis of results from eight randomized, placebo-controlled trials on the effect of cilostazol on patients with intermittent claudication. Am J Cardiol 90: 1314-9.

67. Dawson DL, Cutler BS, Meissner MH, Strandness DE (1998) Cilostazol has beneficial effects in treatment of intermittent claudication: results from a multicenter, randomized, prospective, double-blind trial. Circulation 98: 678-86.

68. Yusuf S, Sleight P, Pogue J, Bosch J, Davies R, et al. (2000) Effects of an angiotensin-converting-enzyme inhibitor, ramipril, on cardiovascular events in high-risk patients. The Heart Outcomes Prevention Evaluation Study Investigators. N Engl J Med 342: 145-53.

69. SPRINT Research Group, Wright JT, Williamson JD, Whelton PK, Snyder JK, et al. (2015) A Randomized Trial of Intensive versus Standard Blood-Pressure Control. N Engl J Med 373: 2103-16.

70. Stone NJ, Robinson JG, Lichtenstein AH, et al. (2013) 2013 ACC/AHA guideline on the treatment of blood cholesterol to reduce atherosclerotic cardiovascular risk in adults: a report of the American College of Cardiology/American Heart Association Task Force on Practice Guidelines. J Am Coll Cardiol. 63: 2889-934.

71. Heart Protection Study Collaborative Group (2007) Randomized trial of the effects of cholesterol-lowering with simvastatin on peripheral vascular and other major vascular outcomes in 20,536 people with peripheral arterial disease and other high-risk conditions. J Vasc Surg 45: 645-54.

72. Vogel TR, Dombrovskiy VY, Galinanes EL, Kruse RL (2013) Preoperative statins and limb salvage after lower extremity revascularization in the Medicare population. Circ Cardiovasc Interv 6: 694-700.

73. Kumbhani DJ, Steg PG, Cannon CP, Eagle KA, Smith SC, et al. (2014) Statin therapy and long-term adverse limb outcomes in patients with peripheral artery disease: insights from the REACH registry. Eur Heart J 35: 2864-72.

74. Belch J, MacCuish A, Campbell I, Cobbe S, Taylor R, et al. (2008) The prevention of progression of arterial disease and diabetes (POPADAD) trial: factorial randomised placebo controlled trial of aspirin and antioxidants in patients with diabetes and asymptomatic peripheral arterial disease. BMJ 337 : a1840.

75. Fowkes FG, Price JF, Stewart MC, Butcher I, Leng GC, et al. (2010) Aspirin for prevention of cardiovascular events in a general population screened for a low ankle brachial index: a randomized controlled trial. JAMA 303: 841-48.

76. Morrow DA, Braunwald E, Bonaca MP, Ameriso SF, Dalby AJ, et al. (2012) Vorapaxar in the secondary prevention of atherothrombotic events. N Engl J Med 366: 1404-13.

77. Bonaca MP, Scirica BM, Creager MA, Olin J, Bounameaux H, et al. (2013) Vorapaxar in patients with peripheral artery disease: results from TRA2\{degrees\} P-TIMI 50. Circulation 127: 1522-9.

78. CAPRIE Steering Committee (1996) A randomised, blinded, trial of clopidogrel versus aspirin in patients at risk of ischaemic events (CAPRIE). CAPRIE Steering Committee. Lancet 348: 1329-39.

79. Armstrong EJ, Anderson DR, Yeo KK, Singh GD, Bang H, et al. (2015) Association of dual-antiplatelet therapy with reduced major adverse cardiovascular events in patients with symptomatic peripheral arterial disease. J Vasc Surg. 62: 157-65. 
80. Cacoub PP, Bhatt DL, Steg PG, Topol EJ, Creager MA (2009) Patients with peripheral arterial disease in the CHARISMA trial. Eur Heart J 30:192-201.

81. Belch JJ, Dormandy J, CASPAR Writing Committee, Biasi GM, Cairols M, et al. (2010) Results of the randomized, placebo-controlled clopidogrel and acetylsalicylic acid in bypass surgery for peripheral arterial disease (CASPAR) trial. J Vasc Surg 52: 825-33.

82. European Stroke Organisation, Tendera M, Aboyans V, Bartelink ML, Baumgartner I, et al. (2011) ESC Guidelines on the diagnosis and treatment of peripheral artery diseases: Document covering atherosclerotic disease of extracranial carotid and vertebral, mesenteric, renal, upper and lower extremity arteries: the Task Force on the Diagnosis and Treatment of Peripheral Artery Diseases of the European Society of Cardiology (ESC). Eur Heart J 32: $2851-906$.

83. Bonvini RF, Rastan A, Sixt S, Noory E, Schwarz T, et al. (2011) Endovascular treatment of common femoral artery disease: medium-term outcomes of 360 consecutive procedures. J Am Coll Cardiol. 58: 792-8.

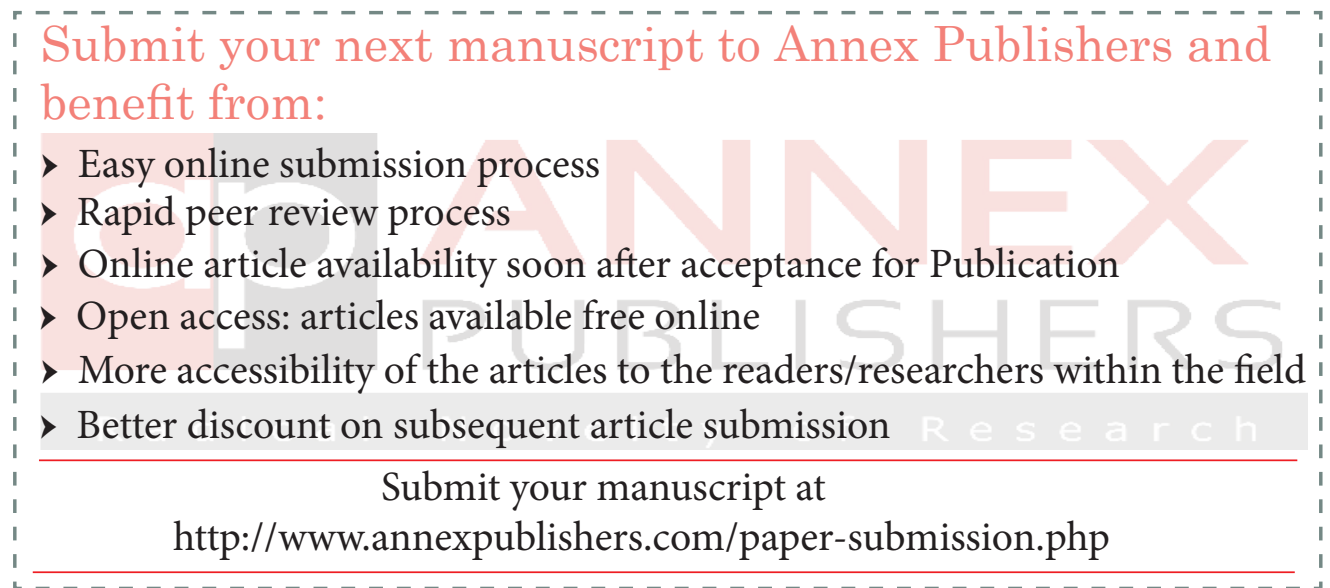

